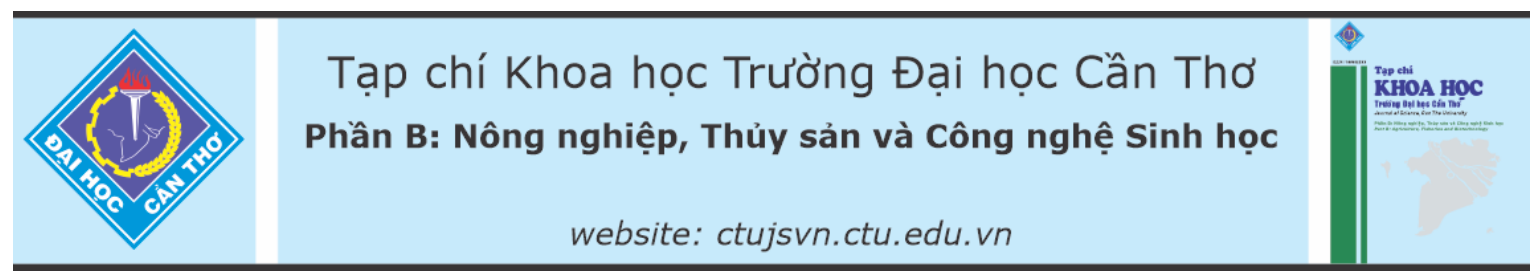

DOI:10.22144/ctu.jvn.2021.180

\title{
TỔNG QUAN: PHÂN LẬP, TUYỂN CHỌN VÀ ÚNG DỤNG NẤM MEN CH!̣U NHIỆT TRONG LÊN MEN RƯợU VANG TRÁI GIÁC
}

Đoàn Thị Kiều Tiên ${ }^{1,2}$, Huỳnh Thị Ngọc Mi2* ${ }^{2 *}$ Huỳnh Xuân Phong ${ }^{2}$, Nguyễn Ngọc Thạnh², Bùi Hoàng Đăng Long ${ }^{2}$, Hà Thanh Toàn ${ }^{2}$ và Ngô Thị Phương Dung ${ }^{2}$

${ }^{1}$ Khoa Công nghệ thực phẩm và Công nghệ sinh học, Truờng Đại học Kỹ thuật - Công nghệ Cần Tho

${ }^{2}$ Viện Nghiên cứu và Phát triển Công nghệ sinh học, Truờng Đại học Cần Tho

*Người chịu trách nhiệm về bài viết: Huỳnh Thị Ngoc Mi (email: sunny2312@cau.ac.kr)

\section{Thông tin chung:}

Ngày nhận bài: $26 / 06 / 2021$

Ngày nhận bài sứa: 08/09/2021

Ngày duyệt đăng: 25/12/2021

Title:

Review: Isolation, selection and application of thermotolerant yeast for cayratia trifolia wine

\section{Tù khóa:}

Khả năng kháng oxy hóa, nấm men chịu nhiệt, polyphenol, ruợu vang, trái giác

\section{Keywords:}

Antioxidant, Cayratia trifolia L., polyphenol, thermotolerant yeast, wine

\begin{abstract}
Threeleaf cayratia (Cayratia trifolia $L$.) has been confirmed to possess high biological activity compounds that are antioxidant and reduce the growth of tumors. Threeleaf cayratia grows naturally in the Mekong Delta region of Vietnam, but there is limited research on this plant. This article provides the results on the isolation and the selection of thermotolerant yeast strains for the applications of wine fermentation in the context of global warming conditions. Out of the threeleaf cayratia samples collected in the Mekong Delta, 151 yeast strains have been isolated and classified into four genera, namely Saccharomyces, Hanseniaspora, Pichia, and Candida. Among them, 64/151 strains could grow at $37^{\circ} \mathrm{C}$ on plates supplemented with 9 to $12 \%$ (volume/volume) ethanol. Threeleaf cayratia fermented wine using selected thermotolerant yeast strains is good in the organoleptic evaluation and contains a high value of total polyphenol which contributes to antioxidant characteristic of the wine.
\end{abstract}

\section{TÓM TẮT}

Trái giác (Cayratia trifolia) đã được nhiều nghiên cúu trên thế giới khẳng định có chứ nhiều hợp chất có hoạt tính sinh họ cao, có khả năng kháng oxy hóa, giảm sụ tăng truởng của khối u. Ỏ Việt Nam, trái giác là một loại trái mọc hoang dại, phổ biến với người dân ở Đồng bằng sông Củu Long, tuy nhiên các nghiên cứu về nó còn hạn chế. Bài viết nhằm cung cấp nhưng kết quả về phân lập nấm men trong tư nhiên, tuyển chọn nhũng chủng nấm men có khả năng chịu nhiệt để ứng dụng vào quá trình lên men ruợu vang đáp úng với điều kiện ấm dần lên của trái đất hiện nay. Tù̀ trái giác trong tư nhiên ở Đồng bằng sông Cửu Long, có 151 chủng nấm men đã được phân lập thuộc bốn giống Saccharomyces, Hanseniaspora, Pichia, và Candida, trong đó có đến 64/151 chủng có khả năng phát triển ở nhiệt độ $37^{\circ} \mathrm{C}$ và chịu được độ cồn đến $9-12 \%$ v/v. Ruợu vang trái giác lên men tù̀ các chủng nấm men chịu nhiệt được tuyển chon cho giá trị cảm quan tốt cũng nhu có sụ hiện diện của thành phần polyphenol khá cao góp phần tạo nên đặc tính kháng oxy hóa của sản phầm. 


\section{GIỚI THIỆ}

Dây giác (Cayratia trifolia) là một loại dây leo thân gố mọc hoang dại trong trảng cỏ và rừng thưa, dọc hàng rào hay các bụi ở các nước như Trung Quốc, Việt Nam, Lào, Campuchia, Thái Lan, Myanma, Indonesia, Malaysia. Trên thế giới, nhiều nghiên cứu cho thấy trong thành phần loài giác có chứa các hợp chất có hoạt tính sinh học cao như phenolic acid, flavonoid, stilbene, anthocyanidin,... các bộ phận khác nhau của giác có chứa dầu sáp màu vàng, steroid, terpenoid, tannin, hydrocyanic acid, ... (Kumar et al., 2011).

Rượu vang có lịch sử hàng ngàn năm, được sản xuất đầu tiên ở các nước Châu Âu. Ngày nay, các sản phẩm rượu vang đã và đang được nghiên cứu để đa dạng hóa về chủng loại, cải tiến về chất lượng, năng suất lẫn quy mô nhằm đáp ứng nhu cầu ngày càng cao của người tiêu dùng. Theo truyền thống, rượu vang được sản xuất từ nho chín, sử dụng nấm men Saccharomyces cerevisiae để nâng cao hiệu quả lên men (Bùi Ái, 2005). Trong quá trình lên men rượu vang, một trong những yếu tố quan trọng nhất chính là nguồn nấm men. Đối với nấm men, nhiệt độ có ảnh hưởng quan trọng đến quá trình chuyển hóa đường thành ethanol (Lương Đức Phẩm, 2009). Hiện nay, nhiệt độ trái đất đang ấm dần lên do hiện tượng biến đổi khí hậu. Nhiệt độ tăng cao sẽ ảnh hưởng đến khả năng lên men của nấm men trong quá trình sản xuất rượu vang cũng như cần phải tiêu tốn một phần năng lượng để giữ ổn định nhiệt độ cho các hệ thống lên men (Limtong et al., 2007; Yuangsaard et al., 2013). Vì vậy, việc lựa chọn nấm men chịu nhiệt để lên men rượu là một giải pháp hữu hiệu mang lại nhiều lợi ích đáng kể như tận dụng được nhiệt độ cao để lên men và giảm chi phí đầu tư cho thiết bị làm mát, từ đó tạo ra nhiều lợi ích kinh tế trong sản xuất (Roehr, 2001; Yuangsaard et al., 2013). Bên cạnh đó, việc phân lập và định danh các chủng nấm men cũng góp phần làm phong phú thêm sự hiểu biết về đa dạng sinh học vi sinh vật.

\section{NÔ̂I DUNG}

2.1. Đặc điểm phân loại, thành phần hóa học và tính chất của loài giác

\subsection{1. Đặc điểm phân loại và điều kiện tụ nhiên của loài giác}

Giác có tên khoa học là Cayratia trifolia (L.) Domin thuộc bộ Vitales (Bảng 1), loài thân leo hóa gỗ và dây leo nhờ tua cuống mọc đối diện ở lá dài khoảng 2-3 cm thường phân ra 3 nhánh (Kumar et al., 2011), đôi khi có 4-5 nhánh có màu nâu đỏ có ít lông, gân dọc. Lá mọc cách kép lông chim, có 3 lá chét ghép lại lá ở giữa thường to hơn hai bên, lá chét có hình trứng thon nhọn dài, gân lá hình lông chim, 6-8 cặp gân phụ, gân lá ở 2 mặt đều có lông dài màu đỏ. Lá già màu xanh lục ở mặt trên, lá non thì có màu xanh hơi đỏ, mặt dưới màu nâu. Thân có tiết diện đa giác, thân già màu xanh, thân non màu nâu đỏ, nhiều gân dọc, ít lông dài. Phát hoa ở nách lá đứng, có thể cao; hoa rộng 6-8 mm, đài hình dĩa, 4 cánh hoa, xanh; tiểu nhụy trượt cánh hoa, dĩa mật vuông, nhuộm đỏ (Phạm Hoàng Hộ, 2000).

Bảng 1. Phân loại khoa học của loài giác $(C$. trifolia)

\begin{tabular}{ll}
\hline Ngành (phylum) & Tracheophyta \\
Lớp (class) & Magnolipsida \\
Bộ (order) & Vitales \\
Họ (family) & Vitaceae \\
Chi (genus) & Cayratia \\
Loài (special) & Trifolia \\
\hline
\end{tabular}

(Kumar et al. (2011))

Các mẫu trái giác thu hái ở Đồng bằng sông Cửu Long (ĐBSCL) có dạng tròn hoặc dẹt, quả mọng có nhiều thịt, nhiều nước, bề mặt trái bóng hoặc hơi nhám có kích thước trung bình khoảng $1,5-2 \mathrm{~cm}$. Dạng trái tròn có lá trơn, bề mặt lá không có lông và có ít răng cưa ở bìa lá; trái dạng dẹt, lá có lông và nhiều răng cưa ở bìa lá (Đoàn Thị Kiều Tiên và ctv., 2018d).

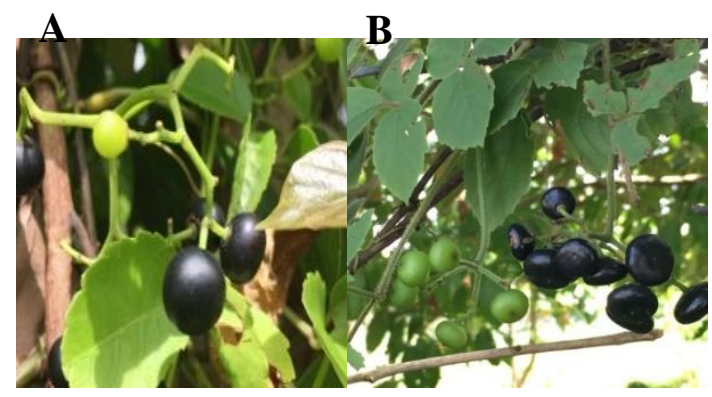

Hình 1. Hình dạng trái giác ở ĐBSCL. A: trái giác dạng tròn, $B$ : trái giác dạng dẹt

(Đoàn Thị Kiều Tiên và ctv., 2018d)

Loài giác sống chủ yếu bám theo các bụi cây hoặc trảng cỏ trong rừng được tìm thấy ở các vùng núi của Ân Độ, ở một phần của vùng nóng Ấn Độ từ Jammu và Rajasthan đến Assam (Kumar et al., 2011). Dây giác phân bố rộng rãi ở các vùng nhiệt đới và cận nhiệt đới, mọc hoang dại ở các trảng cỏ và rừng thưa của Châu Á (Trung Quốc, Thái Lan, Philiphines, Cambodia, Việt Nam, ...), Châu Phi, Úc và các đảo Pacific (Soejima et al., 2005). 
Ở Việt Nam, giác mọc hoang trong các quần thể thứ sinh, dọc các hàng rào, trong các bụi rậm, phân bố từ các tỉnh Lào Cai, Hà Nam, Hải Phòng qua các tỉnh Miền Trung cho đến các tỉnh vùng ĐBSCL như Kiên Giang, An Giang, Cà Mau, Long An, Trà Vinh, ... . Vùng ĐBSCL với khí hậu nhiệt đới đã tạo ra nhiều dạng sinh cảnh tự nhiên, thay đổi từ bãi triều, giồng cát và đầm lầy ngập triều ở vùng ven biển, vùng cửa sông, cho đến vùng ngập lũ, các khu trũng rộng đầm lầy, than bùn, các dãy đất phù sa ven sông và bậc thềm phù sa cổ nằm sâu trong nội địa. Với đất phù sa ngọt, màu mỡ, ít nhiễm phèn và nhiễm mặn, nhiệt độ trung bình quanh năm $28-35^{\circ} \mathrm{C}$, thích hợp cho dây giác mọc hoang khắp nơi. Trái giác được tìm thấy rất nhiều và phổ biến ở vùng rừng $\mathrm{U}$ Minh (Phạm Hoàng Hộ, 2000; Võ Văn Chi, 2004).

\subsubsection{Thành phần hóa học và tính chất của loài giác}

Nhiều công trình nghiên cứu cho thấy dây giác có nhiều công dụng trong việc sử dụng làm thuốc dược liệu, trị liệu, thuốc thú y, ngoài ra còn có hoạt tính kháng oxy hóa, kháng siêu vi, hoạt tính trị ung thư, bảo vệ thần kinh (Kumar et al., 2011). Dây giác sấy khô dạng bột tinh chất kêt hợp acetate và methanol có kết quả thử nghiệm về tính chất kháng oxy hoá nhờ khả năng vô hoạt DPPH $(1,1$ - diphenyl - 2 - picryl hydraryl) rất hiệu quả (Homhual et al., 2007).

Trong lá giác có chứa piceid, resveratrol, viniferin và ampelopsin. Ngoài ra, ở gốc và rễ của giác, theo một số báo cáo có chứa hydrocyanic acid và delphinidin, một số chất flavonoid như cyanogenic được tìm thấy trong hạt và quả (Kumar et al., 2011). Trong thành phần trái có chứa các hợp chất như alkaloid, flavanoid, tannin, protein, phenol, amino acid, carbohydrate, cardioglycoside, saponin, terpenoid and steroid (Sowmya et al., 2015).

Lá và trái có chứa hàm lượng cao phenolic, mẫu dịch trích ethanol có khả năng chống oxy hóa cao (Rabeta \& Lin, 2015). Các chiết xuất ethanolic của toàn bộ loài giác có khả năng làm sạch gốc tự do. Phân tích HPTLC (high-performance thin layer chromatography) đã đánh giá rằng chiết xuất ethanolic của loài giác có năm hợp chất alkaloid và một hợp chất flavonoid, và được báo cáo có hoạt tính chống oxy hóa tương đương thuốc tiêu chuẩn (Perumal et al., 2012).

Giác được sử dụng chữa bệnh tiểu đường, và các bệnh ngoài da như vết thương, khối u, nhọt, cháy nắng, vết cắt, chấn thương và mụn nhọt (Swarnkar \& Katewa, 2008). Tinh chất thô của dây giác được thử nghiệm trong kiểm tra về sinh học sơ bộ cho thấy hoạt tính kháng khuẩn đối với Escherichia coli, Bacillus subtilis , Micrococcus luteus và Penicillium oxalicum (Nick, 1995). Một số chất được trích từ dây giác đã được nghiên cứu như sản phẩm tự nhiên có tác dụng điều trị ung thư.

Nghiên cứu về khả năng chống tiểu đường ở chuột từ dịch trích ở rễ của giác cho thấy các chiết xuất bằng dung môi ethyl acetate có hoạt tính chống tiểu đường mạnh trên chuột ở hai liều $200 \mathrm{mg} / \mathrm{kg}$ và $400 \mathrm{mg} / \mathrm{kg}$ (Batra et al., 2013).

Nghiên cứu khả năng ức chế HER2 (Human epidermal growth factor 2) từ các hợp chất tự nhiên trong $C$. trifolia cho thấy các hợp chất tự nhiên của ethyloleate, 4,8,12,16- tetramethylheptadecan-4olide và heptacosanol có hoạt động ức chế cao HER2 khi so sánh với thuốc được chọn lọc của FDA (Food and Drug Administration) (Perumal et al., 2015).

Khảo sát khả năng kháng oxy hóa của cao chiết ethyl acetate và cao methanol của dây giác bằng phương pháp bắt gốc tự do DPPH cho kết quả ED50 lần lượt là $10,24 \mu \mathrm{g} / \mathrm{mL}$ và $11,36 \mu \mathrm{g} / \mathrm{mL}$ so với chất chuẩn là Trolox là $3,2 \mu \mathrm{g} / \mathrm{mL}$, đồng thời cho thấy hai cao chiết không có khả năng kháng khuẩn đối với 4 dòng vi khuẩn $E$. coli, Staphylococcus aureus, Candida albicans và Aspergillus niger (Homhual et al., 2007).

Các hợp chất chứa trong trái giác có thể giúp chống lại sự lão hóa và ức chế tế bào ung thư, hỗ trợ điều trị ung thư, có khả năng kháng virus, kháng khuẩn, antiprotozoal (chất delphinidin, flavonoid, cayanidin). Trong trái giác có chứa các hợp chất như flavonoid, resveratrol,... có khả năng ngăn chặn quá trình oxy hóa, các hợp chất cyanogenic và alkaloid (36-37mg/g) (Yuangsaard et al., 2013) có đặc tính sinh học phổ biến là tính gây độc tế bào.

Nhiều tài liệu còn cho thấy các loại quả có màu tím chứa nhiều chất flavonoid và anthocyanidin là những chất có hoạt tính cao và tăng cường tính bền chắc cho hệ thống mạch máu. Các loại quả này có tác dụng giảm được nguy cơ nhiễm trùng đường tiết niệu và cải thiện độ chắc của răng. Các chất màu tím có trong nhóm phytochemical còn làm giảm cholesterol, triglyceride và thromboxane giúp ngăn ngừa các bệnh tim mạch, đột quỵ và có khả năng chống lại sự lão hóa, già nua của tế bào (Nguyễn Minh Thủy, 2010). 
Bảng 2. Thành phần hóa lý và khả năng kháng oxy hóa của trái giác ở ĐBSCL

\begin{tabular}{|c|c|c|c|c|c|c|c|}
\hline STT & $\begin{array}{c}\text { Tỉnh/ } \\
\text { thành phố }\end{array}$ & Mẫu & pH & ${ }^{\mathbf{o}}$ Brix & $\begin{array}{r}\text { Hàm lượng } \\
\text { đường khử (g/100mL) } \\
\end{array}$ & $\begin{array}{r}\text { DPPH } \\
(\% \text { ức chế }) \\
\end{array}$ & $\begin{array}{r}\text { Hàm lượng polyphenol } \\
(\mathrm{mg} \mathrm{GAE} / \mathrm{mL})\end{array}$ \\
\hline \multirow{4}{*}{1} & \multirow{4}{*}{ Bạc Liêu } & BL1 & 3,28 & 5 & $0,26^{\mathrm{ijkl}} \pm 0,008$ & $42,97^{\mathrm{ijklmnopqr}} \pm 1,25$ & $1,23^{\text {bcde }} \pm 0,16$ \\
\hline & & BL2 & 3,23 & 4 & $0,26^{\mathrm{ijkl}} \pm 0,005$ & $47,74^{\text {fghijklmno }} \pm 5,42$ & $0,98^{\text {defghij }} \pm 0,07$ \\
\hline & & BL3 & 3,32 & 4 & $0,30^{\text {ghijkl }} \pm 0,012$ & $67,35^{\text {abcdef }} \pm 3,13$ & $1,36^{\mathrm{abc}} \pm 0,03$ \\
\hline & & BL4 & 3,3 & 5 & $0,27^{\mathrm{ijkl}} \pm 0,003$ & $42,71^{\mathrm{ijklmn} o p q r} \pm 5,88$ & $0,67^{\mathrm{klnmopq}} \pm 0,09$ \\
\hline \multirow{4}{*}{2} & \multirow{4}{*}{ Sóc Trăng } & ST1 & 3,52 & 5 & $0,27^{\text {hijkl }} \pm 0,011$ & $42,03^{\mathrm{ijklmnopqr}} \pm 2,73$ & $0,53^{\mathrm{opq}} \pm 0,02$ \\
\hline & & ST2 & 3,39 & 7 & $0,41^{\text {defghijkl }} \pm 0,006$ & $80,26^{\mathrm{ab}} \pm 1,20$ & $1,26^{\mathrm{abcd}} \pm 0,12$ \\
\hline & & ST3 & 3,38 & 4 & $0,26^{\mathrm{ijk}} \pm 0,005$ & $65,86^{\text {abcdefg }} \pm 3,90$ & $1,24^{\mathrm{abcde}} \pm 0,05$ \\
\hline & & ST4 & 3,21 & 5 & $0,33^{\text {fghijkl }} \pm 0,014$ & $41,18^{\mathrm{ijklmnopqrs}} \pm 3,18$ & $0,74^{\mathrm{ijklnmopq}} \pm 0,13$ \\
\hline \multirow{4}{*}{3} & \multirow{4}{*}{ Trà Vinh } & TV1 & 3,51 & 6 & $0,25^{\mathrm{ijkl}} \pm 0,001$ & $45,57^{\text {hijklmnop }} \pm 5,12$ & $0,80^{\text {ghijklmno }} \pm 0,01$ \\
\hline & & TV2 & 3,25 & 5 & $0,25^{\mathrm{ijkl}} \pm 0,005$ & $46,33^{\text {ghijklmnop }} \pm 4,02$ & $0,86^{\text {ghijklmn }} \pm 0,02$ \\
\hline & & TV3 & 3,14 & 4 & $0,25^{\mathrm{ijkl}} \pm 0,003$ & $44,03^{\mathrm{ijklmnopq}} \pm 2,39$ & $0,80^{\text {ghijklmno }} \pm 0,002$ \\
\hline & & TV4 & 3,01 & 4 & $0,26^{\mathrm{ijkl}} \pm 0,014$ & $45,52^{\text {hijklmnop }} \pm 1,33$ & $0,89^{\text {fghijklm }} \pm 0,03$ \\
\hline \multirow{4}{*}{4} & \multirow{4}{*}{ Bến Tre } & BT1 & 3,36 & 6 & $0,26^{\mathrm{ijkl}} \pm 0,005$ & $55,24^{\text {defghij }} \pm 1,65$ & $0,92^{\text {efghijkl }} \pm 0,05$ \\
\hline & & BT2 & 3,41 & 6 & $0,25^{\mathrm{ijkl}} \pm 0,003$ & $48,81^{\text {efghijklmn }} \pm 2,05$ & $0,82^{\text {ghijklmno }} \pm 0,02$ \\
\hline & & BT3 & 3,44 & 7 & $0,55^{\mathrm{cde}} \pm 0,009$ & $51,41^{\text {defghijk }} \pm 4,02$ & $0,93^{\text {efghijkl }} \pm 0,03$ \\
\hline & & BT4 & 3,44 & 7 & $0,36^{\text {efghijkl }} \pm 0,014$ & $70,03^{\mathrm{abcd}} \pm 3,09$ & $1,19^{\text {bcdef }} \pm 0,08$ \\
\hline \multirow{4}{*}{5} & \multirow{4}{*}{ Cà Mau } & CM1 & 3,27 & 5 & $0,30^{\text {ghijkl }} \pm 0,005$ & $21,55^{\text {st }} \pm 2,57$ & $0,90^{\text {fghijkl }} \pm 0,03$ \\
\hline & & CM2 & 3,56 & 6,5 & $0,34^{\text {efghijkl }} \pm 0,048$ & $39,75^{\text {jklmnopqrs }} \pm 6,07$ & $1,07^{\text {cdefg }} \pm 0,02$ \\
\hline & & CM3 & 3,41 & 5 & $0,23^{\mathrm{kl}} \pm 0,043$ & $24,96^{\mathrm{qrst}} \pm 2,18$ & $0,93^{\text {efghijkl }} \pm 0,02$ \\
\hline & & CM4 & 3,55 & 5 & $0,42^{\text {defghijkl }} \pm 0,049$ & $31,31^{\text {lmnopqrst }} \pm 0,47$ & $1,54^{\mathrm{a}} \pm 0,45$ \\
\hline \multirow{4}{*}{6} & \multirow{4}{*}{ Vĩnh Long } & VL1 & 4,08 & 4,5 & $0,23^{\mathrm{kl}} \pm 0,001$ & $40,20^{\mathrm{jklmnopqrs}} \pm 4,00$ & $0,68^{\mathrm{jklnmopq}} \pm 0,02$ \\
\hline & & VL2 & 4,16 & 5 & $0,25^{\mathrm{ijkl}} \pm 0,002$ & $49,19^{\text {efghijkl }} \pm 3,88$ & $0,47^{\mathrm{q}} \pm 0,01$ \\
\hline & & VL3 & 4,71 & 8 & $0,56^{\mathrm{cde}} \pm 0,007$ & $44,50^{\mathrm{ijklmnopq}} \pm 7,32$ & $0,48^{\mathrm{pq}} \pm 0,004$ \\
\hline & & VL4 & 4,75 & 7,5 & $0,28^{\mathrm{ghijkl}} \pm 0,008$ & $64,71^{\text {abcdefgh }} \pm 7,94$ & $0,91^{\text {fghijkl }} \pm 0,03$ \\
\hline \multirow{4}{*}{7} & \multirow{4}{*}{ Tiền Giang } & TG1 & 3,35 & 6 & $0,27^{\text {hijkl }} \pm 0,01$ & $60,57^{\text {bcdefghi }} \pm 2,18$ & $0,75^{\text {hijklmnopq }} \pm 0,10$ \\
\hline & & TG2 & 3,29 & 5 & $0,25^{\mathrm{ijk}} \pm 0,011$ & $51,32^{\text {abcdef }} \pm 3,27$ & $0,78^{\text {ghijklmnopq }} \pm 0,11$ \\
\hline & & TG3 & 3,7 & 8 & $0,81^{\mathrm{ab}} \pm 0,052$ & $66,16^{\text {abcdef }} \pm 0,97$ & $0,69^{\mathrm{ijk} k \mathrm{nmopq}} \pm 0,17$ \\
\hline & & TG4 & 3,7 & 6 & $0,26^{\mathrm{ijk}} \pm 0,006$ & $79,92^{\mathrm{ab}} \pm 4,98$ & $0,83^{\text {ghijklmno }} \pm 0,09$ \\
\hline \multirow{4}{*}{8} & \multirow{4}{*}{ Hậu Giang } & HG1 & 3,35 & 6 & $0,32^{\text {ghijkl }} \pm 0,007$ & $76,90^{\mathrm{abc}} \pm 5,49$ & $1,05^{\text {cdefgh }} \pm 0,09$ \\
\hline & & HG2 & 3,21 & 6 & $0,24^{\mathrm{jkl}} \pm 0,003$ & $67,85^{\text {abcde }} \pm 4,81$ & $0,64^{\mathrm{klmnopq}} \pm 0,12$ \\
\hline & & HG3 & 3,12 & 5 & $0,24^{\mathrm{jkl}} \pm 0,001$ & $76,51^{\mathrm{abc}} \pm 4,09$ & $0,62^{1 \mathrm{lmnopq}} \pm 0,02$ \\
\hline & & HG4 & 3,35 & 4 & $0,30^{\text {ghijkl }} \pm 0,001$ & $27,54^{\mathrm{pqrst}} \pm 4,31$ & $0,54^{\mathrm{opq}} \pm 0,03$ \\
\hline \multirow{4}{*}{9} & \multirow{4}{*}{ Cần Thơ } & CT1 & 3,72 & 8,5 & $0,55^{\text {cdef }} \pm 0,01$ & $65,47^{\text {abcdefg }} \pm 4,92$ & $0,75^{\text {hijklmnopq }} \pm 0,13$ \\
\hline & & $\mathrm{CT} 2$ & 3,6 & 6 & $0,45^{\text {defghijk }} \pm 0,004$ & $28,64^{\text {opqrst }} \pm 2,94$ & $0,57^{\text {nopq }} \pm 0,01$ \\
\hline & & CT3 & 3,78 & 6,5 & $0,63^{\mathrm{bcd}} \pm 0,013$ & $47,70^{\text {fghijklmno }} \pm 8,37$ & $0,94^{\text {efghijk }} \pm 0,06$ \\
\hline & & CT4 & 4,71 & 10 & $0,96^{\mathrm{a}} \pm 0,028$ & $57,54^{\text {cdefghij }} \pm 2,71$ & $0,89^{\text {fghijkl }} \pm 0,05$ \\
\hline & & DT1 & 3,61 & 7 & $0,39^{\text {efghijkl }} \pm 0,029$ & $40,20^{\text {jklmnopqrs }} \pm 1,62$ & $0,82^{\text {ghijklmno }} \pm 0,03$ \\
\hline & & DT2 & 3,6 & 7 & $0,46^{\text {defghi }} \pm 0,022$ & $33,76^{\text {klmnopqrst }} \pm 3,58$ & $0,83^{\text {ghijklmno }} \pm 0,01$ \\
\hline 10 & Đong Thap & DT3 & 3,77 & 8 & $0,49^{\text {cdefgh }} \pm 0,003$ & $40,54^{\mathrm{jklmnopqrs}} \pm 4,19$ & $0,90^{\text {fghijkl }} \pm 0,04$ \\
\hline & & DT4 & 3,46 & 6 & $0,29^{\mathrm{ghijk}} \pm 0,004$ & $45,48^{\text {hijklmnop }} \pm 1,50$ & $0,81^{\text {ghijklmno }} \pm 0,02$ \\
\hline & & AG1 & 4,07 & 4,07 & $0,50^{\text {cdefg }} \pm 0,022$ & $29,41^{\text {mnopqrst }} \pm 3,85$ & $0,90^{\text {fghijkl }} \pm 0,08$ \\
\hline & & AG2 & 4,18 & 4,18 & $0,39^{\text {fghijkl }} \pm 0,025$ & $29,16^{\text {nopqrst }} \pm 1,75$ & $0,88^{\text {ghijklm }} \pm 0,02$ \\
\hline 11 & An Giang & AG3 & 4,04 & 4,04 & $0,39^{\text {efghijkl }} \pm 0,003$ & $43,78^{\mathrm{ijklmnopq}} \pm 4,19$ & $0,99^{\text {defghij }} \pm 0,10$ \\
\hline & & AG4 & 4,3 & 4,3 & $0,46^{\text {defghij }} \pm 0,007$ & $38,24^{\mathrm{jklmnopqrs}} \pm 3,88$ & $0,86^{\text {ghijklmn }} \pm 0,04$ \\
\hline & & LA1 & 3,35 & 6,5 & $0,25^{\mathrm{ijkl}} \pm 0,005$ & $44,71^{\text {ijklmnop }} \pm 2,67$ & $0,64^{\mathrm{klmnopq}} \pm 0,02$ \\
\hline 12 & $\mathrm{I} / \mathrm{ng} \mathrm{An}$ & LA2 & 3,5 & 5,5 & $0,25^{\mathrm{ijk}} \pm 0,007$ & $53,54^{\text {defghij }} \pm 2,78$ & $0,78^{\text {ghijklmnopq }} \pm 0,01$ \\
\hline 12 & Long An & LA3 & 3,9 & 8,5 & $0,71^{b c} \pm 0,013$ & $82,86^{\mathrm{a}} \pm 1,08$ & $1,47^{\mathrm{ab}} \pm 0,09$ \\
\hline & & LA4 & 3,47 & 7 & $0,62^{\mathrm{bcd}} \pm 0,06$ & $44,88^{\text {ijklmnop }} \pm 0,86$ & $0,57^{\text {nopq }} \pm 0,05$ \\
\hline & & KG1 & 3,23 & 3,5 & $0,23^{\mathrm{jkl}} \pm 0,006$ & $29,25^{\text {nopqrst }} \pm 2,15$ & $0,82^{\text {ghijklmno }} \pm 0,05$ \\
\hline & & KG2 & 3,26 & 4 & $0,24^{\mathrm{jkl}} \pm 0,001$ & $23,39^{\text {rst }} \pm 6,78$ & $0,79^{\text {ghijklmnop }} \pm 0,03$ \\
\hline 13 & $\begin{array}{l}\text { Klen } \\
\text { Giano }\end{array}$ & KG3 & 3,1 & 4 & $0,22^{\mathrm{l}} \pm 0,009$ & $32,53^{\text {klmnopqrst }} \pm 1,79$ & $0,70^{\mathrm{ijklnmopq}} \pm 0,03$ \\
\hline & & KG4 & 3,13 & 5 & $0,25^{\mathrm{ijkl}} \pm 0,004$ & $16,61^{ \pm} \pm 5,93$ & $0,58^{\mathrm{mnopq}} \pm 0,12$ \\
\hline & & KG5 & 3,1 & 5 & $0,23^{\mathrm{jkl}} \pm 0,01$ & $49,20^{\text {efghijklm }} \pm 10,90$ & $1,00^{\text {defghi }} \pm 0,07$ \\
\hline
\end{tabular}

Ghi chú: Giá trị trong bảng là giá trị trung bình của 3 lần lập lại, các ký tụ theo sau các giá trị trong cùng một cột, các giá trị có một ký tụ theo sau giống nhau thì khác biệt không ý nghĩa về mặt thống kê ở mức 5\% $(p<0,05)($ (Đàn Thị Kiều Tiên và ctv. (2018d)) 
Đoàn Thị Kiều Tiên và ctv. (2018d) đã công bố trái giác ở 13 tỉnh ĐBSCL có hàm lượng polyphenol cao từ 0,47 đến $1,54 \mathrm{mg} \mathrm{GAE} / \mathrm{ml}$ và khả năng kháng oxy hóa lên đến $82,86 \%$. Nghiên cứu cũng cho thấy hàm lượng polyphenol và hoạt tính kháng oxy hóa của trái giác không bị thay đổi đáng kể sau khi lên men rượu, có thể được xem là nguồn nguyên liệu tiềm năng cho ngành sản xuất rượu vang.

\subsection{Phân lập và tuyển chọn nấm men chịu nhiệt từ các nguồn khác nhau trong tự nhiên}

Nấm men chịu nhiệt ngày càng được quan tâm nhiều hơn về khả năng làm mát nhiệt trong quá trình lên men tạo điều kiện thuận lợi cho việc sản xuất rượu vang hay ethanol sinh học, giảm đáng kể chi phí trong quá rình sản xuất. Yếu tố quan trọng nhất ảnh hưởng đến hoạt động của nấm men là nhiệt độ, để đạt được quá trình lên men ở nhiệt độ cao, cần có chủng nấm men lên men hiệu quả và khả năng chịu nhiệt cao (Limtong et al., 2007). Bên cạnh đó, nấm men chịu nhiệt có một số thuận lợi trong việc sản xuất ethanol trong điều kiện nhiệt độ cao bao gồm: hoạt động trao đổi chất vẫn tốt và tốc độ lên men cao tạo ra nhiều sản phẩm; độ tan của oxy và các khí khác trong nước giảm khi nhiệt độ tăng đảm bảo điều kiện kỵ khí cho quá trình lên men của nấm men; độ nhớt của môi trường lên men giảm khi nhiệt độ tăng nên năng lượng cần thiết cho việc trộn môi trường được giảm đi; cơ hội bị nhiễm được giảm thiểu (Roehr, 2001).

Nấm men chịu nhiệt có thể được phân lập từ các nguồn nguyên liệu tự nhiên đa dạng như: dưa hấu (Ngô Thị Phương Dung và ctv., 2011; Talukder et al., 2016); đất trồng mía (Pongcharoen et al., 2018); trái giác (Doan et al., 2019); khoai tây, thực phẩm phân hủy, chất thải lỏng đô thị, chất thải rắn đô thị, nước mía, pantavat và mật đường (Roehr, 2001), Phoenix dactylifera (Talukder et al., 2019); nước tapé ketan-rượu gạo của Indonesia (Aung et al.,2012). Một số chủng nấm men có khả năng tạo ethanol ở nhiệt độ từ $40^{\circ} \mathrm{C}$ đến $50^{\circ} \mathrm{C}$ được phân lập từ suối nước nóng như RND13 (Ueno et al., 2002).

Trong những năm gần đây, ngày càng có nhiều nghiên cứu về nấm men chịu nhiệt được công bố trong và ngoài nước, các nghiên cứu cũng hướng đến phân lập các chủng nấm men có khả năng sản xuất ethanol ở nhiệt độ cao nhằm giảm chi phí sản xuất và đạt hiệu quả cao hơn trong ngành công nghiệp sản xuất rượu vang và ethanol sinh học. Chamnipa et al. (2014) đã phân lập nấm men chịu nhiệt từ đất, vỏ cây phân rã và cho thấy từ 127 chủng thì có 40 chủng có thể phát triển ở nhiệt độ cao là $37^{\circ} \mathrm{C}, 40^{\circ} \mathrm{C}$ và $45^{\circ} \mathrm{C}$. Buddiwong et al. (2014) cũng đã công bố phân lập được 84 chủng nấm men chịu nhiệt từ đất và bã mía và tuyển chọn được 19 chủng có khả năng sản xuất ethanol ở $45^{\circ} \mathrm{C}$. Nghiên cứu thử nghiệm lên men ethanol ở nhiệt độ cao bằng nấm men chịu nhiệt cho thấy có 18 chủng nấm men chịu được nhiệt tương đối cao ở $43^{\circ} \mathrm{C}$ và 4 chủng phát triển được ở nhiệt độ $45^{\circ} \mathrm{C}$ là $\mathrm{HX} 1, \mathrm{~N} 1, \mathrm{MO}$ và $\mathrm{T}$ (Nguyễn Hữu Tường và ctv., 2013).

Các chủng nấm men Saccharomyces cerevisiae Sc-2, Pichia kudriavzevii Pv-2, Pichia kudriavzevii Tari-2, Pichia kudriavzevii Df-1, Candida tropicalis Mlw-l, Candida tropicalis Bp-2, Pichia guilliermondii $P v-1$ và Candida rugosa $D f-2$ được phân lập từ các nguồn nguyên liệu tự nhiên đa dạng ở Bangladesh có khả năng phát triển ở nhiệt độ từ 37 đến $45^{\circ} \mathrm{C}$, xác định được 18 trong 25 chủng nấm men chịu nhiệt có thể sản xuất ethanol sinh học (Talukder et al., 2016).

Chủng nấm men MBY1358 được xác định là chủng Pichia kudriavzevi đã được tìm thấy từ nuruk (là một nguyên liệu lên men truyền thống của người dân Hàn Quốc) có thể tăng trưởng và sản xuất nồng độ ethanol cao nhất là $8,35 \mathrm{~g} / \mathrm{L}$ ở $44^{\circ} \mathrm{C}$ từ $20 \mathrm{~g} / \mathrm{L}$ glucose (Choi et al., 2017). Huỳnh Xuân Phong và ctv. (2017) cũng đã tuyển chọn được 7 chủng nấm men chịu nhiệt trong 23 chủng phân lập từ khóm được định danh thuộc loài Saccharomyces cerevisiae $(\mathrm{Y} 8, \mathrm{Y} 32, \mathrm{Y} 34, \mathrm{Y} 54, \mathrm{Y} 80$ và $\mathrm{Y} 81)$ và loài Candida glabrata (YVN7). Các kết quả phân lập nấm men chịu nhiệt từ đất trồng mía cho thấy đã phân lập được 30 chủng nấm men phát triển ở nhiệt độ lên đến $45^{\circ} \mathrm{C}$ (Pongcharoen et al., 2018).

Có 151 chủng nấm men đã được phân lập từ nguồn trái giác ở 13 tỉnh ĐBSCL, trong đó tuyển chọn được 30 chủng nấm men chịu nhiệt có khả năng lên men rượu cao tạo ra nồng độ ethanol từ 6,0 đến $9,9 \%$ (v/v) (Doan et al., 2019). 
Bảng 3. Một số chủng nấm men chịu nhiệt trong lên men rượu

\begin{tabular}{|c|c|c|c|c|c|}
\hline STT & Chi & Loài & $\begin{array}{l}\text { Chủng nấm } \\
\text { men }\end{array}$ & Nguồn phân lập & Tài liệu tham khảo \\
\hline 1 & Kluyveromyces & $\begin{array}{l}\text { Kluyveromyces } \\
\text { marxianus }\end{array}$ & IMB3 & $\begin{array}{l}\text { Môi trường nhà } \\
\text { máy chưng cất ở } \\
\text { Ân Độ }\end{array}$ & $\begin{array}{l}\text { Kourkoutas et al. } \\
(2004)\end{array}$ \\
\hline & \multirow{4}{*}{ Candida } & $\begin{array}{l}\text { Candida } \\
\text { tropicalis }\end{array}$ & $\begin{array}{l}\text { KG1.1, KG3.2, } \\
\text { CM3.3, HG3.3, } \\
\text { TG1.1, TG3.1 }\end{array}$ & \multirow{3}{*}{ Trái giác } & \multirow{3}{*}{ Tiên et al. (2019) } \\
\hline 2 & & $\begin{array}{l}\text { Candida } \\
\text { nivariensis }\end{array}$ & $\begin{array}{l}\text { DT1.2, CM3.2, } \\
\text { ST2.1, BT1.2 }\end{array}$ & & \\
\hline & & \multirow{2}{*}{$\begin{array}{l}\text { Candida } \\
\text { glabrata }\end{array}$} & $\begin{array}{l}\text { BL2.1, CT1.1, } \\
\text { CT1.3, CT2.3, } \\
\text { HG2.1 }\end{array}$ & & \\
\hline & & & YVN7 & Trái khóm & $\begin{array}{l}\text { Huỳnh Xuân Phong } \\
\text { và ctv. (2017) }\end{array}$ \\
\hline 3 & & $\begin{array}{l}\text { Issatchenkia } \\
\text { orientalis }\end{array}$ & TB2-1 & $\begin{array}{l}\text { Rượu gạo } \\
\text { Indonesia }\end{array}$ & Aung et al. (2012) \\
\hline 4 & Pichia & $\begin{array}{l}\text { Pichia } \\
\text { kudriavzevii }\end{array}$ & $\begin{array}{l}\text { KG2.1, KG5.1, } \\
\text { AG2.1, AG2.3, } \\
\text { AG4.2, DT3.2, } \\
\text { LA1.3, CM4.4, } \\
\text { BT2.1, BT3.3, } \\
\text { TV4.2, CT4.2, } \\
\text { VL1.1 }\end{array}$ & \multirow[t]{3}{*}{ Trái giác } & \multirow[t]{3}{*}{ Tiên et al. (2019) } \\
\hline 5 & Clavispora & $\begin{array}{l}\text { Clavispora } \\
\text { lusitaniae }\end{array}$ & TG4.2 & & \\
\hline \multirow{3}{*}{6} & \multirow{3}{*}{ Saccharomyces } & \multirow{3}{*}{$\begin{array}{l}\text { Saccharomyces } \\
\text { cerevisiae }\end{array}$} & HG1.3 & & \\
\hline & & & $\begin{array}{l}\text { Y8, Y32, Y34, } \\
\text { Y54, Y80 và Y8 }\end{array}$ & Trái khóm & $\begin{array}{l}\text { Huỳnh Xuân Phong } \\
\text { và ctv. (2017) }\end{array}$ \\
\hline & & & TW1-3 & $\begin{array}{l}\text { Rượu gạo } \\
\text { Indonesia }\end{array}$ & Aung et al. (2012) \\
\hline
\end{tabular}

Khả năng chịu đựng ethanol của đa số các chủng nấm men trong sản xuất rượu bia vào khoảng 5-10 \% (v/v) ethanol (Casey et al., 1986). Khả năng chịu ethanol của các chủng nấm men được xem là một trong những yếu tố quan trọng ảnh hưởng đến khả năng phát triển và sinh ethanol của chúng. Mặc dù ethanol là sản phẩm chính của lên men rượu từ đường, nhưng ở một nồng độ nhất định thì ethanol sẽ ức chế quá trình lên men. Trong quá trình lên men, mật số tế bào thay đổi đáng kể là do nấm men nhạy cảm với ethanol, một số chủng không thể sống sót trong điều kiện ethanol cao. Đồng thời, khả năng chịu ethanol còn phụ thuộc vào nhiệt độ (Torija et al., 2003). Trong 151 chủng nấm men chịu nhiệt phân lập từ trái giác, có 128 chủng nấm men có khả năng phát triển trong môi trường có nồng độ ethanol $6 \%$, còn lại 64 chủng nấm men có khả năng phát triển trong môi trường có nồng độ ethanol $9 \%$, đến giá trị nồng độ ethanol là $12 \%$ thì chỉ còn 27 chủng có thể phát triển và giá trị nồng độ ethanol là $15 \%$ thì không có chủng nào phát triển được. Nhìn chung, các chủng nấm men chịu nhiệt phân lập từ trái giác có khả năng chịu ethanol ở mức trung bình, xác định được có 64 chủng có khả năng chịu ethanol ở mức từ $9 \%$ đến $12 \%$ v/v ethanol (Đoàn Thị Kiều Tiên và ctv., 2018a, 2018c, 2019).

\subsection{Lên men rượu vang trái giác sử dụng nấm men chịu nhiệt}

Nghiên cứu nâng cao chất lượng rượu vang là vấn đề rất được quan tâm hiện nay. Một trong những phương pháp cải tiến chất lượng là sử dụng nguồn nấm men tự nhiên được phân lập từ nguyên liệu cho quá trình sản xuất rượu vang sẽ cho rượu có hàm lượng ethanol cao, chất lượng rượu ổn định và mùi vị đặc trưng (Lương Đức Phẩm, 2009). Nấm men có khả năng đồng hóa nguồn đường cho sinh trưởng, tăng sinh khối và lên men chuyển hóa đường thành rượu. Quá trình lên men rượu có hai sản phẩm chính là ethanol và $\mathrm{CO}_{2}$, để xác định hoạt lực lên men của nấm men có thể dựa trên khả năng thoát khí $\mathrm{CO}_{2}$ trong 
quá trình lên men (Nguyễn Đức Lượng và ctv., 2003).

Saccharomyces cerevisiae là loài nấm men truyền thống được ứng dụng phổ biến trong lên men rượu (Basso et al., 2008). Tại Brazil, các chủng nấm men được sử dụng nhiều nhất là $\mathrm{PE}-2, \mathrm{CAT}-1$ và BG-1, các chủng này được sử dụng trong khoảng 150 nhà máy chưng cất ở Brazil trong giai đoạn 2007-2008. Hầu hết các chủng $S$. cerevisiae chịu được giá trị $\mathrm{pH}$ thấp, hàm lượng đường và nồng độ ethanol cao so với các loài khác, góp phần vào việc làm giảm nguy cơ nhiễm trong quá trình lên men công nghiệp (Nevoigt, 2008). Tuy nhiên, hiệu suất của quá trình lên men của $S$. cerevisiae ở nhiệt độ trên $35^{\circ} \mathrm{C}$ thấp (Ohta et al., 1988).

Theo Doan et al. (2019), có 30 chủng nấm men tuyển chọn được phân tích chuỗi trình tự $26 \mathrm{~S}$ rDNA định danh loài dựa theo cơ sở dữ liệu GenBank (NCBI) cùng với phân tích về hình thái, sinh lý học và sinh hóa của chúng cho thấy tất cả các chủng nấm men chịu nhiệt lên men rượu vang trái giác thuộc bốn giống Saccharomyces, Candida, Clavispora và Pichia.

Chủng nấm men Saccharomyces $\quad s p$. HG1.3 được phân lập từ trái giác được thu hái từ tỉnh Hậu Giang có khả năng lên men rượu vang giác tốt nhất ở $37^{\circ} \mathrm{C}$ với hàm lượng ethanol là $9,9 \%(\mathrm{v} / \mathrm{v})$ (Đoàn Thị Kiều Tiên và ctv., 2018a; Doan et al., 2019).

\subsubsection{Các điều kiện lên men rượu vang trái giác}

Nhiệt độ lên men: Nhiệt độ cần thiết để lên men rượu vang trắng thấp trong khoảng $10-20^{\circ} \mathrm{C}$, còn đối với rượu vang đỏ nhiệt độ lên men cao hơn (lên đến $28^{\circ} \mathrm{C}$ ) (Reynolds et al., 2001). Tuy nhiên, việc sản xuất đồng thời ethanol và malolactic ở nồng độ thấp xảy ra ở nhiệt độ cao lên đến $45^{\circ} \mathrm{C}$ (Nikolaou \& Kourkoutas, 2021). Ngoài ra, quá trình lên men rượu ở nhiệt độ cao đạt chất lượng tốt (Nikolaou \& Kourkoutas, 2021), mùi vị và hương thơm cũng đạt tiêu chuẩn cao (Kourkoutas et al., 2004). Ở các mức nhiệt độ khác nhau trong cùng độ $\mathrm{pH}$, ethanol giảm khi nhiệt độ tăng từ $39^{\circ} \mathrm{C}$ đến $41^{\circ} \mathrm{C}$. Từ nhiệt độ phòng lên $37^{\circ} \mathrm{C}$, nồng độ ethanol sinh ra của các chủng nấm men giảm không nhiều và giảm mạnh khi tăng lên từ $39^{\circ} \mathrm{C}$ lên $41^{\circ} \mathrm{C}$ (Đoàn Thị Kiều Tiên và ctv., 2018e; Tiên et al., 2019). Khi nhiệt độ lên men càng tăng cao thì ethanol càng giảm, điều này chứng tỏ nhiệt độ có ảnh hưởng rất lớn đến sự sinh trưởng, phát triển của nấm men từ đó làm ảnh hưởng đến khả năng lên men. Khi nhiệt độ tăng cao thì lượng ethanol tích lũy nội bào trong tế bào nấm men tăng cao làm ngưng trệ sự phát triển của nấm men (Navarro \& Durand, 1978).
pH lên men: Hàm lượng ethanol cao nhất dao động ở $\mathrm{pH}$ 4,5-4,7, điều này chứng tỏ nồng độ của ion $\mathrm{H}^{+}$có ảnh hưởng đáng kể đến sự lên men do $\mathrm{pH}$ đóng vai trò quan trọng trong việc kiểm soát các vi khuẩn có thể bị nhiễm và ảnh hưởng lên sự phát triển của nấm men. Khi $\mathrm{pH}$ được điều chỉnh lên cao hơn thì acetic acid được tạo thành acetaldehyde dựa vào sự gia tăng hoạt động của enzyme aldehyde dehydrogenase, glycerol được sản sinh và ức chế sự lên men (Wang et al., 2001).

Mật số nấm men và thời gian lên men: Mật số nấm men và thời gian lên men cũng là những yếu tố ảnh hưởng đến sự lên men. Mật số nấm men thấp ở giai đoạn đầu khi được chủng vào cần có thời gian thích nghi, phát triển đến mật số thích hợp và khi thời gian lên men ngắn sẽ làm hạn chế khả năng lên men tối đa của nấm men. Theo nghiên cứu đánh giá khả năng lên men rượu vang trái giác của chủng Saccharomyces cerevisiae CM3.2 đã công bố, nếu mật số giống chủng là $10^{3}$ tế bào/mL thì hàm lượng ethanol của dịch sau lên men đạt 7,70\% khi thời gian lên men trong 5 ngày. Tuy nhiên, khi thời gian lên men kéo dài lên 7 ngày thì hàm lượng ethanol đạt được là $11,77 \% \mathrm{v} / \mathrm{v}$ với $22^{\circ} \mathrm{Brix}$ và mật số là 10 tb/mL (Đoàn Thị Kiều Tiên và ctv., 2019). Cũng trong nghiên cứu này, khi thời gian lên men kéo dài lên 9 ngày thì hàm lượng ethanol giảm xuống còn $11,16 \% \mathrm{v} / \mathrm{v}$, và khác biệt này có ý nghĩa ở mức $5 \%$ $(\mathrm{p}<0,05)$, điều này cho thấy thời gian men cũng tác động đến khả năng lên men của các chủng nấm men. Hàm lượng ethanol khá thấp ở giai đoạn đầu, sau đó mật số nấm men tăng lên và hàm lượng ethanol bắt đầu tăng, hàm lượng đường giảm. Nhưng khi qua giai đoạn tối ưu lên men, nếu kéo dài thời gian lên men khi hàm lượng còn lại quá thấp thì hàm lượng ethanol bắt đầu giảm (Tahir et al., 2010).

Hàm luợng chất khô hòa tan: Ở các nghiên cứu lên men, điều kiện lên men rượu vang cho thấy hàm lượng chất khô hòa tan ban đầu ${ }^{\circ}$ Brix 20 sẽ cho hàm lượng ethanol cao (Casey et al., 1986; Đoàn Thị Kiều Tiên và ctv., 2018c). Hàm lượng đường quá cao sẽ làm tăng áp suất và làm mất cân bằng trạng thái sinh lý của nấm men. Trong lên men, hàm lượng ethanol có liên quan đến hàm lượng đường trong môi trường. Hàm lượng đường thấp, nấm men bị thiếu nguồn dinh dưỡng dẫn đển giảm số lượng sản phẩm nhưng nếu tăng hàm lượng đường quá cao thì hàm lượng ethanol cũng bị giảm (Tahir et al., 2010), vì hàm lượng đường quá cao sẽ làm tăng áp suất thẩm thấu, mất cân bằng trạng thái sinh lý của nấm men. Hàm lượng ethanol sinh ra thấp khoảng $8,05 \%-8,86 \%(\mathrm{v} / \mathrm{v})$ ơ $^{\circ} \mathrm{Brix}$ thấp, và ${ }^{\circ} \mathrm{Brix}$ càng cao thì hàm lượng ethanol sinh ra càng cao đạt tới 
13,47\% (v/v) (Navarro \& Durand, 1978). Tuy nhiên, hàm lượng đường quá cao sẽ làm tăng áp suất và làm mất cân bằng trạng thái sinh lý của nấm, vì vậy cần lựa chọn hàm lượng chất khô hòa tan ban đầu thích hợp cho từng chủng nấm men trước khi tiến hành lên men nhằm đạt được hiệu suất lên men tối ưu nhất.

Trái giác là nguồn nguyên liệu tiềm năng để lên men làm rượu với hàm lượng polyphenol và khả năng chống oxy hóa cao. Rượu vang giác được lên men bởi chủng nấm men chịu nhiệt $S$. cerevisiae AG2.1 ở điều kiện thích hợp là $22,6^{\circ} \mathrm{Brix}, \mathrm{pH} 4$, mật số nấm men chủng là $10^{5}$ tế bào $/ \mathrm{mL}$ và lên men ở $35^{\circ} \mathrm{C}$ sau 6 ngày; độ rượu thành phẩm đạt $11,36 \%$ (v/v) (Đoàn Thị Kiều Tiên và ctv., 2018b). Khi sử dụng chủng nấm men chịu nhiệt $S$. cerevisiae CM3.2 thì điều kiện lên men thích hợp được xác định là $21,09^{\circ} \mathrm{Brix}, \mathrm{pH} 4,5$ với mật số nấm men là $10^{5} \mathrm{tb} / \mathrm{mL}$ và lên men ở nhiệt độ $35^{\circ} \mathrm{C}$ sau 5 ngày lên men; hàm lượng ethanol trong sản phẩm là $12,46 \%$ v/v (Đoàn Thị Kiều Tiên và ctv., 2019).

\subsubsection{Các đặc điểm về chất luợng của ruơuu vang trái giác khi sử dụng chủng nấm men chịu nhiệt được tuyển chọn vào quá trình lên men}

Các chỉ tiêu sinh học và hóa học sau khi lên men trong các nghiên cứu tiếp theo đó đánh giá chất lượng rượu vang trái giác sau khi lên men. Chỉ tiêu sinh tiêu sinh học được đánh giá dựa trên hàm lượng polyphenol và khả năng kháng oxy hóa trước và sau khi lên men rượu. Hàm lượng polyphenol trước khi lên men của dịch trái giác là $0,66 \mathrm{mg} \mathrm{GAE} / \mathrm{mL}$, sản phẩm rượu trái giác sau khi lên men là $0,60 \mathrm{mg}$ $\mathrm{GAE} / \mathrm{mL}$. Sản phẩm rượu vang trái giác khả năng bắt gốc tự do DPPH là $57,3 \%$ thay đổi không đáng kể so với nguyên liệu ban đầu là $54,7 \%$ (Đoàn Thị Kiều Tiên và ctv., 2018d). Hàm lượng polyphenol trong rượu vang trái giác được báo cáo cao hơn so với ba loại rượu mận Crvena ranka, Požegača và Trnovača lần lượt là $0,124,0,145$ và $0,158 \mathrm{mg}$ GAE/mL (Marko et al., 2019).

Các kết quả về chỉ tiêu hóa học và vi sinh vật trong nghiên cứu này cho thấy kết quả kiểm nghiệm các hàm lượng ethanol của rượu vang đạt ở mức $12,0 \% \mathrm{v} / \mathrm{v}$, hàm lượng methanol là $2,534 \mathrm{~g} / \mathrm{L}$, hàm lượng $\mathrm{SO}_{2}$ là $1,4 \mathrm{mg} / \mathrm{L}$ và không phát hiện hàm lượng hydrocyanic acid, các chỉ tiêu phân tích đều đạt theo quy chuẩn Việt Nam (QCVN) 63:2010/BYT. Sản phẩm không phát hiện Colifroms và $E$. Coli (Đoàn Thị Kiều Tiên và ctv., 2018d).

Ngoài ra, nghiên cứu cũng được đánh giá các chỉ tiêu cảm quan theo thang điểm từ $0-5$ với 4 tiêu chí là độ trong và màu sắc, mùi, vị, ý thích đối với mẫu thử dựa trên phương pháp đánh giá cảm quan cho điểm theo tiêu chuẩn Việt Nam TCVN-3217:79 để thể hiện sự yêu thích của người dùng đối với sản phẩm nhằm hướng tới sản xuất loại rượu này ở mức cơ sở trong tương lai. Sản phẩm có độ trong và màu sắc của rượu đạt 4,9 điểm, mùi đạt 4,6 điểm, vị đạt 4,0 điểm, ý thích đối với rượu đạt 4,2 điểm (Đoàn Thị Kiều Tiên và ctv., 2018d).

Bảng 4. Kiểm nghiệm sản phẩm rượu vang trái giác

\begin{tabular}{|c|c|c|c|c|}
\hline STT & Chỉ tiêu & Kết quả & QCVN 6-3:2010/BYT & Nhận xét \\
\hline 1 & Ethanol & $12,0 \% \mathrm{v} / \mathrm{v}$ ơ $20^{\circ} \mathrm{C}$ & $\geq 8 \% \mathrm{v} / \mathrm{v}$ ở $20^{\circ} \mathrm{C}$ & Đạt \\
\hline 2 & Methanol & $2,534 \mathrm{~g} / \mathrm{L}$ rượu $100^{\circ}$ & $10 \mathrm{~g} / \mathrm{L}$ rượu $100^{\circ}$ & Đạt \\
\hline 3 & $\mathrm{SO}_{2}$ & $1,4 \mathrm{mg} / \mathrm{L}$ & $350 \mathrm{mg} / \mathrm{L}$ & Đạt \\
\hline 4 & $\mathrm{pH}$ & 4,17 & & Tự công bố \\
\hline 5 & ${ }^{\circ}$ Brix & 12 & & Tự công bố \\
\hline 6 & Hàm lượng đường khử & $0,26 \mathrm{~g} / 100 \mathrm{~mL}$ & & Tự công bố \\
\hline 7 & Hydrocyanic acid & $0 \mathrm{~g} / \mathrm{L}$ & $0,1 \mathrm{mg} / \mathrm{L}$ & Đạt , \\
\hline 8 & $\begin{array}{l}\text { Rượu bậc cao, tính theo } \\
\text { methyl 2-propanol }\end{array}$ & $2,425 \mathrm{~g} / \mathrm{L}$ rượu $100^{\circ}$ & & Tự công bố \\
\hline 9 & Aldehyde & $0,638 \mathrm{~g} / \mathrm{L}$ rượu $100^{\circ}$ & & Tự công bố \\
\hline 10 & E. coli & 0 CFU/ mL sản phẩm & 0 CFU/ mL sản phẩm & Đạt \\
\hline 11 & Coliforms & 10 CFU/ mL sản phẩm & $\leq 10 \mathrm{CFU} / \mathrm{mL}$ sản phẩm & Đạt \\
\hline 12 & $\begin{array}{l}\text { Tống số vi sinh vật hiếu } \\
\text { khí }\end{array}$ & $7,2 \times 10^{2} \mathrm{CFU} / \mathrm{g}$ & $10^{3} \mathrm{CFU} / \mathrm{g}$ & Đạt \\
\hline 13 & Tổng số nấm men - mốc & $3,6 \times 10^{1} \mathrm{CFU} / \mathrm{g}$ & $10^{2} \mathrm{CFU} / \mathrm{g}$ & Đạt \\
\hline
\end{tabular}

(Đoàn Thị Kiều Tiên và ctv. (2018d)) 


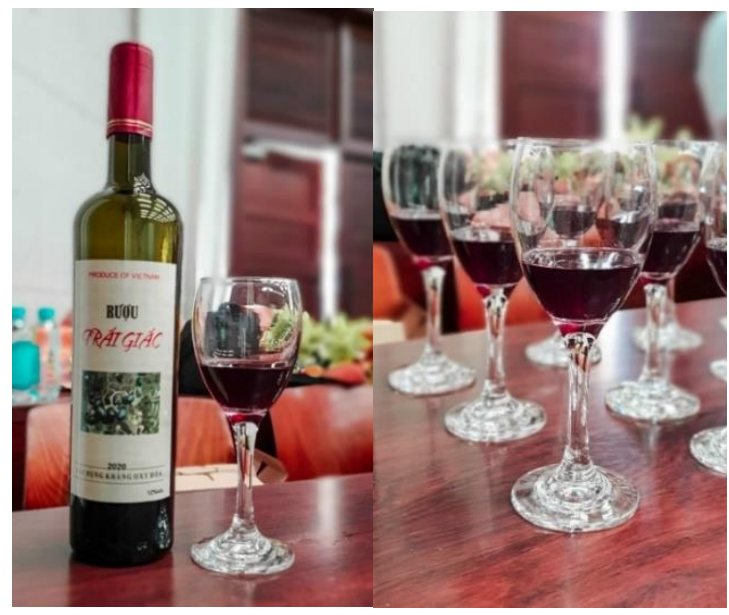

Hình 2. Sản phẩm rượu vang trái giác

\section{KẾT LUẬN}

Nhờ vào các hợp chất kháng oxy hóa cũng như các đặc tính sinh học, giác đã mang lại nhiều lợi ích cho sức khỏe con người. Tất cả các phần của giác (thân, rễ, lá, trái) đều chứa các hợp chất có hoạt tính sinh học như kaempferols, myricetins, quertins, triterpenes, epifriedelanols, polyphenols, steroids/ terpenoids, flavonoids, tannins, ... các chất này có liên quan đến các hoạt động sinh học có lợi như khả năng chống oxy hóa, kháng khuẩn, kháng ung thư, trị bệnh tiểu đường, bệnh ngoài da. Thêm vào đó, trái giác còn được sử dụng như một loại gia vị trong nấu ăn và là nguồn nguyên liệu dồi dào cho ngành lên men rượu.

Nấm men chịu nhiệt ngày càng khẳng định được vai trò của nó trong sản xuất ethanol sinh học hay tngành công nghiệp lên men, mang lại hiệu quả cao, giảm chi phí sản xuất. Đã có nhiều chủng nấm men chịu nhiệt được phân lập để sử dụng lên men rượu thuộc các giống Kluyveromyces, Candida, Pichia, Clavispora, Saccharomyces. Trong 151 chủng nấm men phân lập được từ trái giác, có 30 chủng được xác định có khả năng phát triển ở nhiệt độ $37-45^{\circ} \mathrm{C}$, đóng góp vào sự đa dạng và phong phú hơn cho nguồn nấm men trong ngành lên men.

Bên cạnh đó, rượu vang trái giác lên men từ nấm men chịu nhiệt được đánh giá cảm quan tốt, thích hợp với cảm quan của người dùng, đạt tiêu chuẩn quy định, đặc biệt hàm lượng polyphenol và khả năng kháng oxy hóa của trái giác vẫn không thay đổi sau thời gian lên men. Qua đó cho thấy rượu vang trái giác được lên men từ các chủng nấm men chịu nhiệt sẽ là sản phẩm đặc trưng và tiềm năng trong sản xuất rượu vang ở Việt Nam nói chung và vùng ĐBSCL nói riêng. Đồng thời, việc nghiên cứu về bảo quản, duy trì màu sắc cũng như thành phần hoạt tính sinh học của rượu vang trái giác là cần thiết nhằm nâng cao chất lượng và phát huy giá trị của sản phẩm.

\section{TÀI LIỆU THAM KHẢO}

Aung, W., Watanabe, Y., \& Hashinaga, F. (2012). Isolation and phylogenetic analysis of two thermotolerant, fermentative yeast strains from liquid Tapé Ketan (Indonesian Rice Wine). Food Sci Technol Res, 18(2), 143-148. https://doi.org/10.3136/fstr.18.143

Batra, S., Batra, N., \& Nagori, B. P. (2013). Preliminary phytochemical studies and evaluation of antidiabetic activity of roots of Cayratia trifolia (L.) Domin in alloxan induced diabetic albino rats. Journal of Applied Pharmaceutical Science, 3(3), 97-100.

Basso, L. C., Amorim, H. V., Oliveira, A. J., \& Lopes, M. L. (2008). Yeast selection for fuel ethanol production in Brazil. Federation of European Microbiological Societies, 8(7), 11551163. https://doi.org/10.1111/j.15671364.2008.00428.x

Buddiwong, S., Thanonkeo, S., Phetsom, J., Jaisil P., \& Thanonkeo, P. (2014). Screening of thermotolerant yeast isolated from sugarcane plantations in Northeastern part of Thailand. KKU Research Journal, 19, 217-223.

Bùi Ái. (2005). Công nghệ lên men úng dụng trong Công nghệ Thưcc phẩm. Đại học Quốc gia TP.Hồ Chí Minh.

Casey, G. P., \& Ingledew, W. M. M. (1986). Ethanol tolerance in yeast. Crit Rev Microbiol, 13(3), 219280. https://doi.org/10.3109/10408418609108739

Chamnipa, N., Thanonkeo, S., \& Thanonkeo, P. (2014, November 26-29). Isolation and identification of thermotolerant yeast for ethanol production at high temperature. The $26^{\text {th }}$ Annual of Meeting of the Thai Society for Biotechnology and International Conference, Chiang Rai, Thailand.

Choi, D. H., Park, E. H., \& Kim, M. D. (2017). Isolation of thermotolerant yeast Pichia kudriavzevii from nuruk. Food Science and Biotechnol, 26(5), 1357-1362. https://doi.org/10.1007/s10068-017-0155-6

Dung, N. T. P., Thanonkeo, P., \& Phong, H. X. (2012). Screening useful isolated yeasts for ethanol fermentation at high temperature. International Journal of Applied Science and Technology, 2(4), 65-71.

Đoàn Thị Kiều Tiên, Viên Thị Hải Yến, Bùi Hoàng Đăng Long, Huỳnh Xuân Phong, Hà Thanh Toàn \& Ngô Thị Phương Dung. (2018a). Tuyển chọn nấm men chịu nhiệt và ứng dụng lên men rượu 
vang trái giác (Cayratia trifolia L.) từ tỉnh Hậu Giang. Tạp chi Khoa hoc Truòng Đại hoc Cần Tho, 54(4b), 64-71.

https://doi.org/10.22144/ctu.jvn.2018.071

Đoàn Thị Kiều Tiên, Lữ Hằng Nghi, Nguyễn Ngọc Thạnh, Huỳnh Xuân Phong, Hà Thanh Toàn \& Ngô Thị Phương Dung. (2018b). Phân lập và tuyển chọn nấm men chịu nhiệt ứng dụng trong lên men rượu vang trái giác (Cayratia trifolia L.). Tạp chí Nông Nghiệp và Phát Triển Truòng Đại học Nông Lâm TP. Hồ Chí Minh, 2, 55-61.

Đoàn Thị Kiều Tiên, Huỳnh Thị Hoàng Anh, Nguyễn Ngọc Thạnh, Huỳnh Xuân Phong, Hà Thanh Toàn \& Ngô Thị Phương Dung. (2018c). Tuyển chọn nấm men chịu nhiệt lên men rượu vang trái giác (Cayratia trifolia L.) của tỉnh Kiên Giang. Tạp chi Khoa học và Phát triển Nông Thôn, 2, 54-62.

Đoàn Thị Kiều Tiên, Huỳnh Thị Ngọc Mi, Nguyễn Đức Độ, Hà Thanh Toàn \& Ngô Thị Phương Dung. (2018d). Khảo sát hàm lượng polyphenol và khả năng kháng oxy hóa của dịch trái giác (Cayratia trifolia) trước và sau lên men sử dụng nấm men chịu nhiệt Saccharomyces cererevisiae HG1.3). Tạp chi Khoa học và Công nghệ Việt Nam, 60(8), 60-44.

Đoàn Thị Kiều Tiên, Huỳnh Thị Ngọc Mi, Huỳnh Thị Hoàng Anh, Huỳnh Xuân Phong, Nguyễn Ngọc Thạnh, Bùi Hoàng Đăng Long, Hà Thanh Toàn \& Ngô Thị Phương Dung. (2018e). Hoạt tính sinh học của trái giác thu ở tỉnh Kiên Giang và lên men rượu vang trái giác sử dụng Saccharomyces cerevisiae AG 2.1 Trong: Hội nghị toàn quốc về công nghệ sinh học. Ngày 26 tháng 10, Trung tâm Hội nghị Quốc gia Việt Nam, Hà Nội, Việt Nam. Tạp chi Khoa học và công nghệ Việt Nam, 978-983.

Đoàn Thị Kiều Tiên, Huỳnh Thị Ngọc Mi, Lữ Hằng Nghi, Huỳnh Xuân Phong, Nguyễn Ngọc Thạnh, Bùi Hoàng Đăng Long, Hà Thanh Toàn \& Ngô Thị Phương Dung. (2019). Đánh giá khả năng duy trì hàm lượng polyphenol và hoạt tính kháng oxy hóa khi lên men rượu vang từ trái giác ở tỉnh Cà Mau sử dụng Saccharomyces cerevisiae CM3.2. Tạp chí Khoa học Truờng Đại học Cần Tho, 55(2), 285-291. https://doi.org/10.22144/ctu.jsi.2019.072

Homhual, S., Tongngok, P., Sonsrakhu, S., \& Bonjim J. (2007). Evaluation of Biological Activities of Crude Extracts from Cratoxylum formosum (Jack.) Dyer. and Cayratia trifolia L. Domin Young Shoots, J Ubon Rajathanee Uni, 9, 54-60.

Huỳnh Xuân Phong, Danh Minh Lợi, Nguyễn Ngọc Thạnh, Lê Phan Đình Quí, Bùi Hoàng Đăng Long, Thanonkeo P., Yamada M., \& Ngô Thị Phương Dung. (2017). Tuyển chọn nấm men chịu nhiệt và nghiên cứu điều kiện lên men rượu vang khóm. Tạp chí Khoa học Truờng Đại học
Cần Tho, 51(B), 7-15.

https://doi.org/10.22144/ctu.jvn.2017.073

Kourkoutas, Y., Mcerlean, C., Kanellaki, M., Marchant, C. J. Hack, R., Banat, I. M., \& Koutinas, A. A. (2004). High-Temperature Wine Making Using the Thermotolerant Yeast Strain Kluyveromyces marxianus IMB3. Appl Biochem Biotechnol, 112(1), 25-35. https://doi.org/10.1385/ABAB:112:1:25

Kumar, D., Kumar, S., Gupta, J., Arya, R., \& Gupta, A. (2011). A review on chemical and biological properties of Cayratia trifolia Linn. (Vitaceae). Pharmacognosy Reviews, 5(10), 184-188. https://doi.org/10.4103/0973-7847.91117

Limtong, S., Sringiew C., \& Yongmanitchai, W. (2007). Production of fuel ethanol at high temperature from sugar cane juice by a newly isolated Kluyveromyces marxianus. Bioresource Technology, 98, 3367-3374. https://doi.org/10.1016/j.biortech.2006.10.044

Lương Đức Phẩm (2009). Nấm men công nghiệp. NXB Khoa học và Kỹ thuật.

Marko, L., Milka, J., Jovana, S., Branko, P., Ninoslav, N., Aleksandar, P., \& Vele, T. (2019). Phenolic composition and DPPH radical scavenging activity of plum wine produced from three plum cultivars. Journal of the Serbian Chemical Society, 84(2), 141-151. https://doi.org/10.2298/JSC180710096L

Navarro, J. M., \& Durand, G. (1978). Alcohol fermentation: effect of temperature on ethanol accumulation within yeast cells. Annals of Microbiology. 129B(2), 215 - 224.

Nevoigt, E. (2008). Progress in metabolic engineering of Saccharomyces cerevisiae. Microbiol Molecular Biology Revolution, 72(3), 379 - 412. https://doi.org/10.1128/MMBR.00025-07

Nikolaou, A., \& Kourkoutas, Y. (2001). Hightemperature semi-dry and sweet low alcohol wine-making using immobilized kefir culture. Fermentation-MPDI, 7(2), 45. https://doi.org/10.3390/fermentation7020045

Ngô Thị Phương Dung, Lý Huỳnh Liên Hương \& Huỳnh Xuân Phong. (2011). Phân lập, tuyển chọn nấm men và xác định điều kiện ảnh hưởng quy trình lên men rượu vang dưa hấu. Tạp chí Khoa học Truòng Đại học Cần Tho', 18b, 137-145.

Nguyễn Đức Lượng, Phan Thị Huyền \& Nguyễn Ánh Tuyết. (2003). Thi nghiệm công nghệ sinh hoc tập 2, thí nghiệm vi sinh vật học. NXB Đại quốc gia TP Hồ Chí Minh.

Nguyễn Hữu Tường, Phạm Hồng Quang, Ngô Thị Phương Dung, Huỳnh Xuân Phong \& Nguyễn Minh Đời. (2013). Thử nghiệm lên men ethanol ở nhiệt độ cao bằng nấm men chịu nhiệt. Tạp chi Khoa học Trưòng Đại học Cần Tho, 27, 16-23. 
Nguyễn Minh Thủy. (2010). Ổn định và nâng cao chất lượng rượu vang sim bằng phương pháp hóa học và sinh học. Tap chi Khoa học Truờng Đại hoc Cần Tho, 14, 195-204.

Nick, A. (1995). Biological Screening of Traditional Medicinal Plant from Papua New Guinea and subsequent phytochemical investigation of Dillenia Papuana, Doctoral Theses (Diss. ETH No. 11231). Zürich: Swiss Federal Institute of Technology, 2-5.

Ohta, K., Wijeyaratne, S. C., Hayashida, S. (1988). Temperature-sensitive mutants of a thermotolerant yeast Hansenula polymorpha. Journal Fermentation Technology, 66, 455-459. https://doi.org/10.1016/0385-6380(88)90014-3

Perumal, P. C., Sophia, D., Raj, C. A., Ragavendran, P., Starlin, T., \& Gopalakrishnan, V. K. (2012). In vitro antioxidant activities and HPTLC analysis of ethanolic extract of Cayratia trifolia (L.). Asian Pacific Journal of tropical disease, 2(2), 952-956. https://doi.org/10.1016/S22221808(12)60299-0

Perumal, P. C., Pratibha, P., Sowmya, S., Enock, K. O., Anusooriya, P., Vidya, B., Malarvizhi, D., Poornima, K., Ramkumar, S., \& Gopalakrishnan V. K. (2015). Discovery of Novel Inhibitors for HER2 from Natural Compounds Present in Cayratia trifolia (1): An In silico Analysis. International Journal of Current Pharmaceutical Review and Research, 6(3), 164-168.

Phạm Hoàng Hộ. (2000). Cây cỏ Việt Nam quyển II. Nhà xuất bản trẻ.

Phong, H. X., Giang, N.T.C., Nitiyon S., Yamada M., Thanonkeo P., \& Dung N.T.P. (2016). Ethanol production from molasses at high temperature by thermotolerant yeasts isolated from cocoa. Can Tho University Journal of Science, 3, 32-37. https://doi.org/10.22144/ctu.jen.2016.021

Pongcharoen, P., Chawneua, J., \& Tawong, W. (2018). High temperature alcoholic fermentation by new thermotolerant yeast strains Pichia kudriavzevii isolated from sugarcane field soil. Agriculture and Natural Resources, 52(6), 511518. https://doi.org/10.1016/j.anres.2018.11.017

Rabeta, M. S., \& Lin, S. P. (2015). Effects of different drying methods on the antioxydant activities of leaves and berries of Cayratia trifolia. Sains Malaysiana, 44(2), 275-280. https://doi.org/10.17576/jsm-2015-4402-16

Reynolds, A., Cliff, M., Ginard, B., \& Kopp, T. (2001). Influence of fermentation temperature on composition and sensory properties of Semillon and Shiraz wines. Am J Enol Vitic, 52(3), 235-240.

Roehr, M. (2001). The Biotechnology of Ethanol: Classical and Future Applications. Federal
Republic of Germany, 6(12), 1019-1020. https://doi.org/10.3390/61201019

Soejima, A., \& Wen, J. (2015). Phylogenetic analysis of Grape Family (Vitaceae) based on three chloroplast markers. American Journal of Botany, 93(2), 278-287. https://doi.org/10.3732/ajb.93.2.278

Sowmya, S., Perumal, P. C., Anusooriya, P., Vidya, B., Pratibha, P., Malarvizhi, D., \& Gopalakrishnan, V. K. (2015). Comparative preliminary phytochemical analysis various different parts (stem, leaf and fruit) of Cayratia trifolia (L.). Indo American Journal of Pharmaceutical Research, 5(1), 218-222.

Swarnkar, S., \& Katewa, S. S. (2008). Ethnobotanical observation on tuberous plant from tribal areas of Rajasthan (India). Ethnobotanical Leaflets, 12, 647-666.

Tahir, A., Aftab, M., \& Farasat, T. (2010). Effect of cultural conditions on ethanol production by locally isolated Saccharomyces cerevisiae bio07. Journal of Applied Pharmacy, 3(2), 72-78.

Talukder, A. A., Easmin, F., Mahmud, S. A., \& Yamada, M. (2016). Thermotolerant yeasts capable of producing bioethanol: isolation from natural fermented sources, identification and characterization. Agriculture and Environmental Biotechnology, 1106-1114. https://doi.org/10.1080/13102818.2016.1228477

Talukder, A. A., Adnana, N., Siddiqa, A., Miah, R., Tuli, J. F., Khan, S. T., Dey, S. K., Lertwattanasakul, N., \& Yamada, M. (2019). Fuel ethanol production using xylose assimilating and high ethanol producing thermosensitive Saccharomyces cerevisiae isolated from date palm juice in Bangladesh. Biocatalysis and Agricultural Biotechnology, 18(1), 101029. https://doi.org/10.1016/j.bcab.2019.101029

Torija, M. J., Rozès, N., Poblet, N., Guillamón, J. M., \& Mas, A. (2003). Effects of fermentation temperature on the strain population of Saccharomyces cerevisiae. International Journal of Food Microbiology, 80(1), 47-53. https://doi.org/10.1016/S0168-1605(02)00144-7

Doan, T. K. T, Huynh, X. P., Yamada, M., Ha, T. T., \& Ngo, T. P. D. (2019). Characterization of newly isolated thermotolerant yeasts and evaluation of their potential for use in Cayratia trifolia wine production. Vietnam J. Sci. Technol. Eng. 61(1), 68-73. https://doi.org/10.31276/VJSTE.61(1).68-73

Ueno, R., Urano, N., \& Kimura, S. (2002). Effect of temperature and cell density on fermentation by a thermotolerant aquatic yeast strain isolated from a hot spring environment. Fisheries science, 68, 571-578. 
https://doi.org/10.1046/j.14442906.2002.00463.x

Võ Văn Chi (2004). Tù điển thực vật thông dụngtập 1. Nhà xuất bản Khoa học và kỹ thuật.

Wang, Z. X., Zhuge, J., Fang, H., \& Prior, B. A. (2001). Glycerol production by microbial fermentation: A review. Biotechnology Advances, 19(3), 201-223.

https://doi.org/10.1016/S0734-9750(01)00060-x
Yuangsaard, N., Yongmanitchai, W., Yamada, M., \& Limtong, S. (2013). Selection and characterization of a newly isolated thermotolerant Pichia kudriavzevii strain for ethanol production at high temperature from cassava starch hydrolysate. Antonie van Leeuwenhoek, 103(3), 577-588.

https://doi.org/10.1007/s10482-012-9842-8 